\title{
Intraspecific predation in the Liolaemus lizard radiation: a primer
}

\author{
Daniel Pincheira-Donoso* \\ Centre for Ecology and Conservation, College of Life \& Environmental Sciences, University of \\ Exeter, Streatham Campus, Exeter, EX4 4PS, Devon, United Kingdom
}

Accepted: September 16, 2011

\begin{abstract}
Intraspecific predation (cannibalism) occurs in a number of lizard species, although the incidence of this trophic behaviour appears to be infrequent. Within the South American Liolaemus lizard evolutionary radiation, the primary component of the carnivorous diet (herbivory has also evolved in several species) includes a diversity of arthropods and other invertebrates. However, a number of cases of saurophagy, mostly cannibalism, have also been reported in different species. Here, I review for the first time the occurrence of cannibalism in this prominent group of lizards, one of the largest and more ecologically diverse living adaptive radiations. Adults of five Liolaemus species have previously been reported to feed on conspecific hatchlings, and one additional case (L. zapallarensis) is reported in this paper. In general, cannibalism is found in species located at the right side of the body size frequency distribution, while no cases have been reported on the far left range of body sizes, suggesting that cannibalism is more common in large species. Only one species of medium size ( $L$. darwinii) is known to feed on conspecifics. In addition, males are responsible for $83 \%$ of the cases of cannibalism, while only one case of female cannibalism is known (L. chiliensis). Finally, no clear phylogenetic signal can be inferred from these observations, as the six reported cannibal species belong to four of the five main Liolaemus clades.
\end{abstract}

(c) Koninklijke Brill NV, Leiden, 2012.

\section{Keywords}

Saurophagy; cannibalism; trophic ecology; lizards; Liolaemus

\section{Introduction}

Intraspecific predation, or cannibalism, is a widespread ecological behaviour in the animal kingdom from invertebrates to vertebrates (Fox, 1975; Polis, 1981), including humans (Shankman, 1969). Theory and evidence suggest that cannibalism may

*) E-mail: D.PincheiraDonoso@exeter.ac.uk 
have multiple origins across organisms, sometimes as a result of rather stochastic events involving opportunistic attacks of (often) large individuals on smaller conspecifics, or as a deterministic (adaptive) result of selection-mediated benefits of intraspecific predation on fitness (Polis, 1981; Pfennig, 1997; Pough et al., 2004; Lourdais et al., 2005). The dynamics of adaptive cannibalism, in turn, vary depending on the selective regimes experienced by populations, resulting in either habitual cannibalism or in context-dependent cannibalism that takes place as a result of fluctuating episodes of selection that demand predation on conspecifics under certain circumstances (Fox, 1975; Polis, 1981; Elgar and Crespi, 1992). Among amphibians, for example, where cannibalism is widespread and well investigated, a number of studies have shown that larger (older) size classes feed on smaller (younger) conspecifics when or where food availability declines (Crump, 1992; Pfennig, 1997; Pizzatto and Shine, 2008). Indeed, under extreme conditions of food stress, some species can temporarily switch to a primarily cannibalistic diet (Pizzatto and Shine, 2008). Given that cannibalism can be common and temporarily predominant, its consequences on population dynamics, ecological interactions and life histories are thought to be potentially substantial (Polis, 1981; Elgar and Crespi, 1992).

Among reptiles, intraspecific predation is not as common as in amphibians, although it has been documented in several species from different clades (Polis and Myers, 1985; Mitchell, 1986). In general, cannibalistic behaviour in these animals has been regarded as being mostly opportunistic, and hence, an incidental nonadaptive result of encounters between size (age) classes (Polis and Myers, 1985; Pough et al., 2004). However, some studies on cannibalism in lizards have revealed that some saurophagous species may discriminate between similarly sized conspecifics and heterospecifics during predation, reducing the frequency of cannibalistic attacks (Rand and Andrews, 1975; Jenssen et al., 1989). These observations suggest that avoidance of conspecifics as prey may indeed have a genetic basis, and hence, lower rates of cannibalism may be mediated by selection, which is not the same as being simply opportunistic. Regardless of the extent of stochasticity or selective determinism behind cannibalistic behaviour, predation on conspecifics may promote anti-predator adaptive responses in the fraction of the population (ediblesized) that suffer predation, resulting in evolutionary effects of cannibalism (e.g. Castilla and Van Damme, 1996), even when it is opportunistic. However, the overall extent of ecological and evolutionary significance of cannibalism is likely to depend on the frequency with which this behaviour takes place within lineages, from species to higher categories, and not simply on how widespread it is among major clades. Hence, observations of cannibalism across a broad diversity of animal clades (e.g. classes or orders) do not necessarily indicate that intraspecific predation is ecologically and evolutionarily significant within each of these clades. Therefore, it is important to synthesize the occurrence of cannibalism within clades.

In this paper, I review the occurrence of intraspecific predation within the prominent Liolaemus lizard radiation. A remarkable phylogenetic, morphological, behavioural, ecological, and life history diversity has evolved during at least 13 mil- 
lion years in this lizard lineage (Schulte et al., 2000, 2004; Harmon et al., 2003; Espinoza et al., 2004; Morando et al., 2004; Labra et al., 2009; Pincheira-Donoso et al., 2009; Pincheira-Donoso and Tregenza, 2011). These features make Liolaemus an interesting group to explore alternative evolutionary strategies in response to the natural selection demands (such as predation) encountered during their radiation across a diversity of environments, one of the widest known for a single lizard genus (Pincheira-Donoso et al., 2008a; Labra et al., 2009). However, cases of cannibalism in Liolaemus are scattered in the form of short natural history notes that are rarely indexed in scientific databases. Hence, a review of this phenomenon is needed.

\section{Diet and cannibalism in Liolaemus}

Liolaemus lizards have evolved a diversity of trophic adaptations from predominant herbivory to (almost) exclusive arthropophagy, with a large number of omnivorous species between both extremes (Jaksic, 1998; Espinoza et al., 2004; O'Grady et al., 2005; Pincheira-Donoso, 2008; Pincheira-Donoso et al., 2008b). This dietary variation has been shown to be directly associated with geographical distribution, where the proportion of herbivory increases as a function of increasing latitude and elevation, and hence, with decreasing climatic temperature (Espinoza et al., 2004). The animal composition of Liolaemus species diet is remarkable, ranging from apparent specializations in small prey items such as ants, to a number of different invertebrate preys found in single specimens, including insects in general and their larvae, spiders, scorpions, and snails, among several others (Donoso-Barros, 1966; Cei, 1986, 1993; Jaksic, 1998; Pincheira-Donoso, 2008, unpubl. data). However, the animal diet of these lizards does not only include invertebrates, but also expands into other Liolaemus species (i.e. saurophagy), as reported in some studies (e.g. Avila and Belver, 2000; Avila and Morando, 2002; Perez et al., 2009). Part of this Liolaemus component in the diet of some Liolaemus species includes conspecifics, revealing cannibalism.

Traditional foraging theory suggests the existence of two major foraging strategies, 'active foraging' and 'sit-and-wait (or ambush) foraging', which have been present since the origin of the two major extant squamate lineages (although active foraging is thought to be ancestral), Scleroglossa and Iguania, respectively (Vitt and Pianka, 2005, 2007). According to this foraging dichotomy, Iguanian lizards would be opportunistic eaters, and hence, would feed on any appropriately sized organism passing by. Given that Liolaemus are iguanians, and hence, regarded as primarily sit-and-wait predators (although active foragers are likely to be present within the genus), it would be expected that a diversity of animal prey are opportunistically and unselectively targeted by these lizards (which is also consistent with the wide variety of organisms consumed by Liolaemus both among and within species). Small lizards (compared to the size of the predator) dwelling around a Liolaemus would therefore be expected to serve as food. As indicated above, this may be the case, 
Table 1.

Summary of Liolaemus species that have been found to incur in cannibalism. No data on prey is available for $L$. chiliensis (report based on a tail) and L. rothi. Likewise, only general references to cannibalism are reported for $L$. baguali, with no specifications on sex or size of the cannibals or prey.

\begin{tabular}{llccl}
\hline \multirow{2}{*}{ Species } & \multicolumn{2}{c}{ Cannibal } & & Reference \\
\cline { 2 - 3 } & Sex & SVL (mm) & Prey size & \\
\hline L. baguali & - & - & $-{ }^{\mathrm{a}}$ & Scolaro (2005) \\
L. chiliensis & female & 76.6 & $-{ }^{\mathrm{a}}$ & Pincheira-Donoso (2000) \\
L. darwinii & male & 54 & 25 & Ripoll and Acosta (2007) \\
L. huacahuasicus & male & - & $-{ }^{\mathrm{a}}$ & Halloy and Halloy (1997) \\
L. lutzae & male & 67.2 & 29 & Rocha (1992) \\
& male & 67.6 & 30 & \\
L. rothi & male & 81 & $-\mathrm{b}$ & Kozykariski et al. (2009) \\
L. zapallarensis & male & 72.75 & 28.4 & This study \\
\hline
\end{tabular}

a Although no body size data is provided, cannibalism occurs on newborns.

b This report indicates that the prey is a "juvenile".

c This report needs confirmation. Cannibalism in this species is considered "possible" and only one attempt of cannibalism observed in an experimental setting suggest it may take place. See text for details.

as shown in a number of field observations where saurophagy has been reported within Liolaemus. However, Liolaemus species are not only known to exhibit interspecific saurophagy. Some cases of cannibalism on young conspecifics have been reported in the literature. As summarized in table 1, the existing literature contains five demonstrated cases in species belonging to four different clades within Liolaemus. Liolaemus baguali (Scolaro, 2005) within the lineomaculatus clade, L. darwinii (Ripoll and Acosta, 2007) and L. rothi (Kozykariski et al., 2009) within the boulengeri clade, L. lutzae (Rocha, 1992a) within the wiegmannii clade, and $L$. chiliensis (Pincheira-Donoso, 2000) within the chiliensis clade (table 1; fig. 1). An additional case of "possible" cannibalism was reported in L. huacahuasicus (montanus clade) by Halloy and Halloy (1997). These authors observed an adult male attacking a conspecific newborn in an experimental setting, which needs further confirmation in the wild before regarding this report as a demonstrated case of intraspecific predation in the genus. Finally, it is worth noting that Ripoll and Acosta (2007) refer to two additional cases of cannibalism in Liolaemus, in the species L. koslowskyi and L. petrophilus, citing Avila and Belver (2000) and Avila and Morando (2002). However, both papers reported cases of interspecific saurophagy (on hatchlings of other Liolaemus species: L. pseudoanomalus and L. bibronii, respectively) rather than intraspecific predation.

In this paper, I report an additional case of cannibalism in L. zapallarensis, a large-sized, oviparous species from the Atacama Desert (Chile), member of the chiliensis clade, and which was recently reported as being almost exclusively herbivorous (Espinoza et al., 2004). However, previous studies (see Jaksic, 


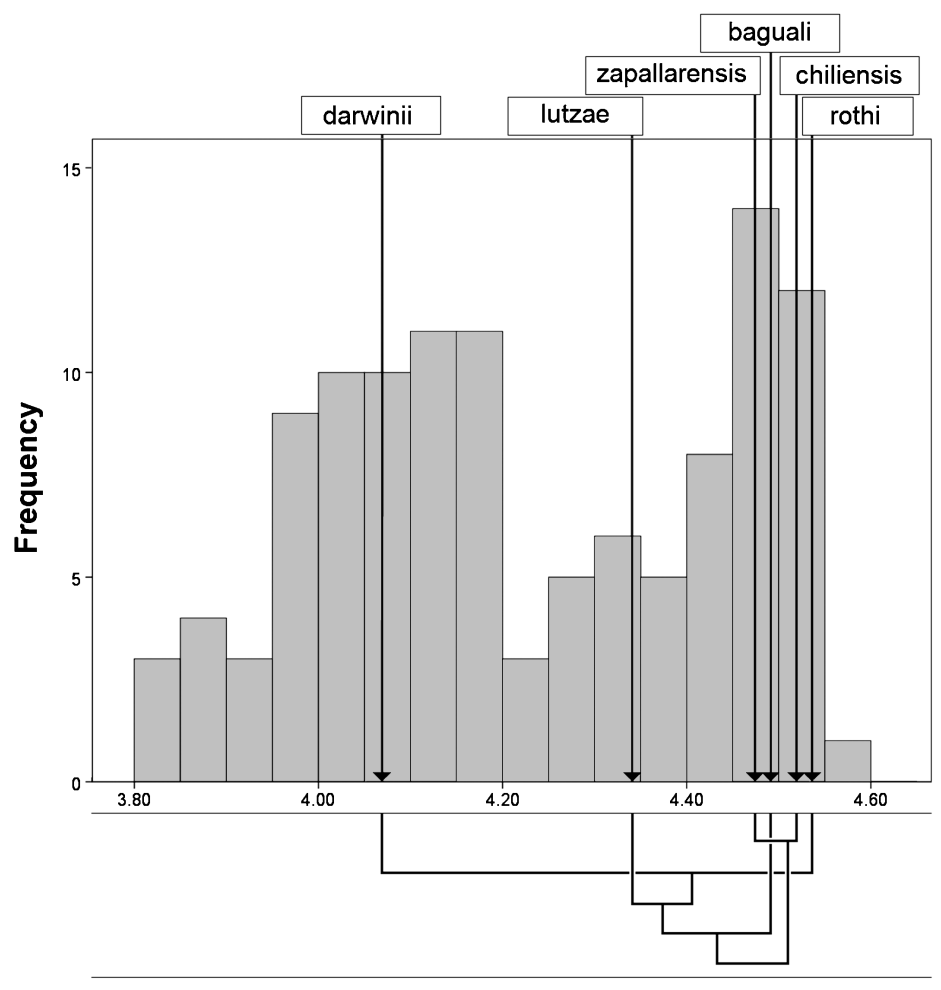

In(Snout-Vent Length)

Figure 1. Body size frequency distribution (natural logarithm, ln) of 115 species of Liolaemus belonging to all main clades known for this genus, indicating with a vertical black arrow the body size position of the six reported cannibal species. The suspected case of cannibalism in L. huacahuasicus (see table 1) needs confirmation, and hence, it has been excluded from this figure where only confirmed cases are included. Body size per species is the average of male and female body sizes calculated separately (rather than an average calculated from a sample containing both males and females). To calculate sex-specific average adult body sizes for males and females, I calculated means from the largest two-thirds of the available specimens per sex (this percentile provides a reliable measure of adult size in lizards). Five of the six cannibal Liolaemus species are displaced towards the right side of the size frequency distribution, indicating that cannibalism might be more likely to occur in larger species. Phylogenetic relationships (according to Espinoza et al., 2004) among cannibal species are depicted at the bottom of the plot. Finally, it is worth noting the unusual bimodal shape of the body size distribution found in this genus.

1998; and references therein) and ongoing ecological analyses (unpubl. data) reveal that this lizard consumes a variety of animals (mostly arthropods), including newborns of its own species as reported here. The cannibal lizard was an adult male ( $72.75 \mathrm{~mm}$ snout-vent length, SVL) collected on Los Lobos Island $\left(31^{\circ} 54^{\prime} \mathrm{S}\right.$, $71^{\circ} 31^{\prime} \mathrm{W} ;<20$ masl), located about $5 \mathrm{~km}$ off the coast of the locality of Los Vilos (on the $25^{\text {th }}$ January, 1981). Within the stomach of this specimen, apart from a $20 \%$ volume of plant matter, the recorded arthropod diversity included 14 hemipterans (from two unidentified species) and five different unidentified species of spiders. 
The lizard prey is a whole conspecific hatchling ( $28.4 \mathrm{~mm} \mathrm{SVL})$, whose sex could not be determined. Within a sample of additional 42 adult L. zapallarensis specimens from both sexes where dietary contents were analyzed (DPD, unpubl. data), no other case of cannibalism was found (a cannibalism frequency of $2.3 \%$ for this sample). For the genus Liolaemus in general, the frequency of cases of cannibalism is below $3 \%$, considering the approximately 220 known species (Pincheira-Donoso et al., 2008b). This proportion is likely to change as further studies on the trophic ecology of Liolaemus are conducted.

Available data on intraspecific predation in Liolaemus suggests that no phylogenetic signal exists for cannibal species, as the five cases are spread across four major lineages (see above; fig. 1). In addition, five of six cannibal species (83.3\%) are located at the right side of the body size frequency distribution, while only one species of medium size ( $L$. darwinii) is known to feed on conspecifics (fig. 1). Cannibalism has never been reported on the far left range of Liolaemus body sizes; hence, this behaviour is more common in large species. Finally, cannibalism is male-biased. Males are responsible for $83.3 \%$ of the reported cases of cannibalism (table 1), while only one case of a female cannibal, in L. chiliensis, is known (table 1). If the case of $L$. huacahuasicus is taken into account (table 1), this frequency increases to $85.7 \%$, reinforcing the male tendency to feed on conspecifics.

\section{Discussion}

This study reviews the still poorly explored occurrence of cannibalistic behaviour within the Liolaemus lizard adaptive radiation. To the best of my knowledge, only six confirmed cases (including the new case reported in this paper; table 1) of intraspecific predation have been reported in the literature within this genus. However, given the low frequency of these cases relative to the number of samples studied per species in each case, it seems reasonable to expect that cannibalism may occur in other Liolaemus species for different reasons (e.g. opportunistic encounters, periods of food shortage, or different forms of ecological and sexual competition). This speculation may be strengthened by the fact that detailed studies of the dietary ecology in Liolaemus remain restricted to a small proportion of species. Nevertheless, while more cases of cannibalism are possible, the reported cases suggest that this behaviour is likely to be infrequent in general. In his classic review, Polis (1981) argues against previous studies where cannibalism was regarded as an uncommon behaviour, stating that it is in fact widespread. However, it is important to frame these discussions in a phylogenetic context and hence, make a distinction between widespread occurrence among animals as a whole, and the extent of frequency within lineages. Although cannibalism is common to several organisms, it tends to be uncommon within lineages, as it is the case in Liolaemus.

Despite the limited number of cases of cannibalism known in Liolaemus, and hence, the difficulties to confidently infer quantitative correlates of cannibalism, some interesting patterns emerge from the available data. First, that cannibalism 
seems more likely to occur in large sized species (fig. 1). This is an intuitive expectation, which has largely been shown in the literature (Polis, 1981; Pough et al., 2004). In Liolaemus, all cases of cannibalism consist of adults feeding on hatchlings or juveniles. Second, there is a strong sexual bias towards male cannibalism (83\%), while only one female case is known in this genus. This observation contrasts with the global data presented by Polis (1981), where $86 \%$ of cases showed that females were more cannibalistic. On the other hand, examples of male-biased cannibalism have also been shown in a number of animals, ranging from invertebrates to vertebrates (Rotary and Gerling, 1973; Hrdy, 1979; Polis, 1981; Gray et al., 2007). Interestingly, in a recent multilineage study on lizard saurophagy, Siqueira and Rocha (2008) showed that male cannibalism is predominant when males are bigger than females (male-biased sexual size dimorphism), while it is restricted to females when sexual dimorphism is female-biased. This is the case in Liolaemus. All cases of male cannibalism come from species where males are the larger sex, while the only case of female cannibalism comes from L. chiliensis, where females are the larger sex (sexual dimorphism observations according to Pincheira-Donoso and Tregenza, 2011). Nevertheless, although the available information suggests an important sexual bias and potentially a link with sexual size dimorphism, further observations are needed to strengthen this preliminary conclusion, which should be taken with caution. Finally, the third pattern observed is that no phylogenetic effects seem to be associated with cannibalism, as cases of intraspecific predation are evenly spread across most major Liolaemus lineages (apart from the suspected report of cannibalism in L. huacahuasicus [table 1], no clear cases are known within the montanus clade) (fig. 1).

Despite the observation of some patterns involved in cannibalism, the causes behind this behavior remain difficult to establish at present. As a generality, it seems to be that larger body size tends to facilitate intraspecific predation (Polis, 1981; Pough et al., 2004; Siqueira and Rocha, 2008). Cannibalism may result from large body size or large body size may result from the need to access a higher diversity of food items, including juvenile conspecifics. The first alternative reflects a mostly opportunistic scenario, where cannibalism simply occurs whenever a juvenile approaches an adult, and hence, does not imply an adaptive origin. On the other hand, cannibalism may be a context-dependent plastic behavior that expresses when natural selection arising from food competition intensifies under resource shortage, or may have adaptively evolved as a habitual behavior (i.e. context-independent). These two latter cases in the second alternative imply a genetic (adaptive) basis (the extent of phenotypic plasticity is itself evolvable), and have been shown to take place in nature. For example, it has been shown in a number of animals that during periods of lower food availability or in environments where resources are consistently limited, cannibalism may have a higher incidence (Fox, 1975; Polis, 1981; Pough et al., 2004). According to Polis (1981), three factors would explain this plasticity phenomenon: increased foraging activity under food stress, higher frequency of weak and vulnerable individuals after periods of food deprivation, and 
the need to expand trophic breadth during periods of hunger, as traditionally predicted by foraging theory. In more strictly adaptive scenarios, it has been shown for example in the tiger salamander (Ambystoma tigrinum), that regular cannibalism of adults on larvae is associated with morphological (e.g. enlarged jaw muscles) and behavioural traits that facilitate intraspecific predation (Duellman and Trueb, 1994; Pough et al., 2004). Given that cannibalism seems to be infrequent in Liolaemus, the later alternative that this behavior is a habitual adaptive feeding strategy appears to be a less likely explanation than the opportunistic and plasticity alternatives.

Apart from inferences based on the particularly low frequencies of cannibalism observed in Liolaemus, the idea that this behaviour is strictly adaptive is in fact difficult to rule out. However, it is more plausible to conceive studies that may test whether cannibalism is mostly context-dependent or simply opportunistic. The simplest studies would involve associations of cases of intraspecific predation with environmental fluctuations known to influence the ecological dynamics of resource exploitation, and with ecological outcomes known to result as responses to these fluctuating selection episodes. For example, variation in the frequency of cannibalism between seasons where food abundance fluctuates, or between environments that offer different abundances of food. In the tropical species L. lutzae (arguably the most thoroughly studied species of the entire genus) two cases of cannibalism have been reported (Rocha, 1992a; table 1). Seasonal shifts in the diet of this species are known to occur between summer and winter, with higher proportional consumption of plants during the later season, when arthropod abundance declines (Rocha, 1996). In both seasons, proportions of consumed food are predicted by abundance of consumed items, which suggests at least some degree of opportunism (Rocha, 1996; see Rocha, 2000; for selectivity in plant consumption). Both cases of cannibalism took place in the summer, when arthropod abundance is high (Rocha, 1996), but also, when abundance of conspecific hatchlings is high (Rocha, 1992b). Therefore, collectively, these observations suggest that, in L. lutzae, the incidence of intraspecific predation is more compatible with an opportunistic scenario, which has been suggested to be the main explanation behind cannibalism among lizards in general (Polis and Myers, 1985; Pough et al., 2004). The fact that cannibalism has been found when arthropod and hatchling abundances are higher (and that, in general, diet and prey availability are strongly correlated) indicates that these lizards do not predate on conspecific as a strategy to mitigate the ecological costs faced during periods of low arthropod availability. No similar detailed ecological information is available for other Liolaemus species where cannibalism has been found, and hence, no similar inferences on the possible causes of intraspecific predation are possible.

Finally, it remains possible that no single cause explains all cases of cannibalistic behaviour in this genus. Within a prominent radiation like Liolaemus, similar adaptive outcomes are likely to have arisen as a result of different ecological and evolutionary dynamics, under different selective contexts. Therefore, while some cases may be simply opportunistic, others may well have been driven by some 
extent of fitness advantage conferred to cannibals. This is a realistic scenario in lineages where foraging modes (i.e. active or ambush) differ between species, and hence, the degree of selectivity in prey consumption differs. In species where foraging mode is active rather than ambush, adaptive cannibalism (or adaptive avoidance of cannibalism) may take place, resulting in different origins of intraspecific predation within the same clade.

\section{Acknowledgements}

I thank J.C. Acosta, L.J. Avila, C.F.D. Rocha, and J. A. Scolaro for providing essential literature on cannibalism and saurophagy in Liolaemus, and R. Langstroth for critically reading the manuscript. Two anonymous referees provided insightful comments to improve the final version of this work. I also thank H. Núñez for the permission to examine the dietary contents of Liolaemus species preserved in the National Museum of Natural History of Santiago Herpetological Collection. This study was funded by the Leverhulme Trust and received additional support from the CRIDESAT (University of Atacama, Chile) through an honorary fellowship.

\section{References}

Avila, L.J. \& Belver, L. (2000) Liolaemus koslowsky: saurophagy. Herpetol. Rev., 31, 174.

Avila, L.J. \& Morando, M. (2002) Liolaemus petrophilus: saurophagy. Herpetol. Rev., 33, 52.

Castilla, A.M. \& Van Damme, R. (1996) Cannibalistic propensities in the lizard Podarcis hispanica atrata. Copeia, 1996, 991-994.

Cei, J.M. (1986) Reptiles del Centro, Centro-Oeste y Sur de la Argentina. Herpetofauna de las Zonas Áridas y Semiáridas. Museo Regionale di Scienze Naturali di Torino, Torino.

Cei, J.M. (1993) Reptiles del Noroeste, Nordeste y Este de la Argentina. Herpetofauna de las Selvas Subtropicales, Puna y Pampas. Museo Regionale di Scienze Naturali di Torino, Torino.

Crump, M.L. (1992) Cannibalism in amphibians. In: M.A. Elgar \& B.J. Crespi (Eds.) Cannibalism. Ecology and Evolution among Diverse Taxa, pp. 256-276. Oxford University Press, Oxford.

Donoso-Barros, R. (1966) Reptiles de Chile. Ediciones Universidad de Chile, Santiago.

Duellman, W.E. \& Trueb, L. (1994) Biology of Amphibians. Johns Hopkins University Press, Maryland.

Elgar, M.A. \& Crespi, B.J. (1992) Cannibalism. Ecology and Evolution among Diverse Taxa. Oxford University Press, Oxford.

Espinoza, R.E., Wiens, J.J. \& Tracy, C.R. (2004) Recurrent evolution of herbivory in small, coldclimate lizards: breaking the ecophysiological rules of reptilian herbivory. Proc. Natl. Acad. Sci. USA, 101, 16819-16824.

Fox, L.R. (1975) Cannibalism in natural populations. Ann. Rev. Ecol. Syst., 6, 87-106.

Gray, S.M., Dill, L.M. \& McKinnon, J.S. (2007) Cuckoldry incites cannibalism: male fish turn to cannibalism when perceived certainty of paternity decreases. Am. Nat., 169, 258-263.

Halloy, M. \& Halloy, S. (1997) An indirect form of parental care in a high altitude viviparous lizard, Liolaemus huacahuasicus (Tropiduridae). Bull. Maryl. Herpetol. Soc., 33, 139-155.

Harmon, L.J., Schulte, J.A., Larson, A. \& Losos, J.B. (2003) Tempo and mode of evolutionary radiation in iguanian lizards. Science, 301, 961-964. 
Hrdy, S. (1979) Infanticide among animals: a review, classification, and examination of the implications for reproductive strategies of females. Ethol. Sociobiol., 1, 13-40.

Jaksic, F.M. (1998) Ecología de los Vertebrados de Chile. Ediciones Universidad Católica de Chile, Santiago.

Jenssen, T.A., Marcellini, D.L., Buhlmann, K.A. \& Goforth, P.H. (1989) Differential infanticide by adult curly-tailed lizards, Leiocephalus schreibersi. Anim. Behav., 38, 1054-1061.

Kozykariski, M., Goldman, J., Olave, M. \& Avila, L.J. (2009) Liolaemus rothi: cannibalism. Herpetol. Rev., 40, 89.

Labra, A., Pienaar, J. \& Hansen, T.F. (2009) Evolution of thermal physiology in Liolaemus lizards: adaptation, phylogenetic inertia, and niche tracking. Am. Nat., 174, 204-220.

Lourdais, O., Brischoux, F., Shine, R. \& Bonnet, X. (2005) Adaptive maternal cannibalism in snakes (Epicrates cenchria maurus, Boidae). Biol. J. Linn. Soc., 84, 767-774.

Mitchell, J.C. (1986). Cannibalism in reptiles: a worldwide review. Soc. Stud. Amphib. Rept. Herpetol. Circular, 15, 1-37.

Morando, M., Avila, L.J., Baker, J. \& Sites, J.W. (2004) Phylogeny and phylogeography of the Liolaemus darwinii complex (Squamata: Liolaemidae): evidence for introgression and incomplete lineage sorting. Evolution, 58, 842-861.

O'Grady, S.P., Morando, M., Avila, L.J. \& Dearing, M.D. (2005) Correlating diet and digestive tract specialization: examples from the lizard family Liolaemidae. Zoology, 108, 201-210.

Perez, C.H.F., Perez, D.R. \& Avila, L.J. (2009) Liolaemus austromendocinus: saurophagy. Herpetol. Rev., 40, 222-223.

Pfennig, D.W. (1997) Kinship and cannibalism. BioScience, 47, 667-675.

Pincheira-Donoso, D. (2000) Hallazgo de predación intraespecífica en Liolaemus chilensis (Lesson, 1831) (Sauria-Tropiduridae). Rev. Integr. Biol. Concepción, 1, 33-35.

Pincheira-Donoso, D. (2008) Testing the accuracy of fecal-based analyses in studies of trophic ecology in lizards. Copeia, 2008, 322-325.

Pincheira-Donoso, D., Hodgson, D.J. \& Tregenza, T. (2008a) The evolution of body size under environmental gradients in ectotherms: why should Bergmann's rule apply to lizards? BMC Evol. Biol., 8,68 .

Pincheira-Donoso, D., Scolaro, J.A. \& Sura, P. (2008b) A monographic catalogue on the systematics and phylogeny of the South American iguanian lizard family Liolaemidae (Squamata, Iguania). Zootaxa, 1800, 1-85.

Pincheira-Donoso, D., Hodgson, D.J., Stipala, J. \& Tregenza, T. (2009) A phylogenetic analysis of sex-specific evolution of ecological morphology in Liolaemus lizards. Ecol. Res., 24, 1223-1231.

Pincheira-Donoso, D. \& Tregenza, T. (2011) Fecundity selection and the evolution of reproductive output and sex-specific body size in the Liolaemus lizard adaptive radiation. Evol. Biol., 38, $197-$ 207.

Pizzatto, L. \& Shine, R. (2008) The behavioral ecology of cannibalism in cane toads (Bufo marinus). Behav. Ecol. Sociobiol., 63, 123-133.

Polis, G. \& Myers, C.A. (1985) A survey of intraspecific predation among reptiles and amphibians. J. Herpetol., 19, 99-107.

Polis, G.A. (1981) The evolution and dynamics of intraspecific predation. Ann. Rev. Ecol. Syst., 12, 225-251.

Pough, F.H., Andrews, R.M., Cadle, J.E., Crump, M.L., Savitzky, A.H. \& Wells, K.D. (2004) Herpetology. Pearson, Prentice Hall, New Jersey.

Rand, A.S. \& Andrews, R.M. (1975) Adult color dimorphism and juvenile pattern in Anolis cuvieri. J. Herpetol., 9, 257-260. 
Ripoll, Y. \& Acosta, J.C. (2007) Liolaemus darwinii: cannibalism. Herpetol. Rev., 38, 459.

Rocha, C.F.D. (1992a) Liolaemus lutzae (sand lizard): cannibalism. Herpetol. Rev., 23, 60.

Rocha, C.F.D. (1992b) Reproductive and fat body cycles of the tropical sand lizard (Liolaemus lutzae) of southeastern Brazil. J. Herpetol., 26, 17-23.

Rocha, C.F.D. (1996) Seasonal shift in lizard diet: the seasonality in food resources affecting the diet of Liolaemus lutzae (Tropiduridae). Cien. Cult. Sao Paulo, 48, 264-269.

Rocha, C.F.D. (2000) Selectivity in plant food consumption in the lizard Liolaemus lutzae from southeasten Brazil. Stud. Neotrop. Fauna Environ., 35, 14-18.

Rotary, N. \& Gerling, D. (1973) The influence of some external factors upon the sex ratio of Bracon hebetor Say (Hymenoptera: Braconidae). Environ. Entomol., 2, 132-138.

Schulte, J.A., Macey, J.R., Espinoza, R.E. \& Larson, A. (2000) Phylogenetic relationships in the iguanid lizard genus Liolaemus: multiple origins of viviparous reproduction and evidence for recurring Andean vicariance and dispersal. Biol. J. Linn. Soc., 69, 75-102.

Schulte, J.A., Losos, J.B., Cruz, F.B. \& Núñez, H. (2004) The relationship between morphology, escape behaviour and microhabitat occupation in the lizard clade Liolaemus (Iguanidae: Tropidurinae: Liolaemini). J. Evol. Biol., 17, 408-420.

Scolaro, J.A. (2005) Reptiles Patagónicos Sur. Una Guía de Campo. Editorial Universidad Nacional de la Patagonia, Trelew.

Shankman, P. (1969) Le Rôti et le Bouilli: Lévi-Strauss' theory of cannibalism. Am. Anthropol., 71, 54-69.

Siqueira, C.C. \& Rocha, C.F.D. (2008) Predation by lizards as a mortality source for juvenile lizards in Brazil. S. Am. J. Herpetol., 3, 82-87.

Vitt, L.J. \& Pianka, E.R. (2005) Deep history impacts present day ecology and biodiversity. Proc. Natl. Acad. Sci. USA, 102, 7877-7881.

Vitt, L.J. \& Pianka, E.R. (2007) Feeding ecology in the natural world. In: S.M. Reilly, L.D. McBrayer \& D.B. Miles (Eds.) Lizard Ecology: The Evolutionary Consequences of Foraging Mode, pp. 141172. Cambridge University Press, Cambridge. 